$\begin{array}{llllllllllllllllllll}A & R & T & I & C & U & L & O & D & E\end{array}$

$\begin{array}{lllllllll}R & E & F & L & E & X & I & O & N\end{array}$

\section{LA FOTOGRAFía de Jorge OrTIZ, REVELANDO PAISAJES}

\author{
JORGE ORTIZ FOTOGRAPHY, REVEALING LANDSCAPES
}

Por: Mónica Lucía Molina Saldarriaga*

* Magíster en Estética de la Universidad $\mathrm{Na}$ cional de Colombia, docente en ejercicio en ins tituciones de educación superior de diferentes universidades en la ciudad de Medellin en la cual reside tales como sitaria Bellas Artes, la sitaria Bellas Artes, la
Universidad Pontificia Bolivariana y la Universidad Cooperativa de Colombia.

1"La generación de artistas que irrumpe en el ámbito nacional a lo largo de los años setenta, que se consolida, en términos generales, en los ninos generales, en ma con especial interés ma con especial interés las problemas urbanos. Se debe destacar en ellos la conciencia de que la historia del país ha cambiado y que, a diferenci de las ciudades míticas, llenan, por ejemplo, las pinturas de Fernando Botero, ahora se impone la áspera realidad de ciudades que crecen vertiginosamente y enfrentan las más agudas crisis urbenísticas y sociales de su histicas y sociales de su 1970 y 1990, las ciudades colombianas sufren agresiones de todo tipo, que producen la sensación de un deterioro irreversible donde se pierce el patrimonio histórico centros urbanos casi por completo en manos del hampa, mientras, con frecuencia, las ideas de modernización no hacen más que agravar el estado de las cosas y llevan incluso hasta la perdicta del paisaje natuurbana, está en acto una crisis generalizada de valores en el país. En este contexto, resulta apenas obvia la preocupación de las nuevas generaciones por enfrentarse al do de la ciudad [...]" (Fernández, Arte en Colombia:1981-2006, 2007)
Recibido: 11 de marzo 2016 - Aprobado: 10 de junio de 2016

\section{RESUMEN}

Jorge Ortiz, es uno de los artistas más relevantes en la historia de la fotografía artística en Colombia. Él propone una nueva perspectiva para la producción y la reflexión en torno a la configuración de un nuevo lenguaje fotográfico, en el cual confluyen relaciones pictóricas, conceptuales con la exploración de las técnicas fotográficas. El artículo pretende explorar el lenguaje construido por el maestro Jorge Ortiz a través de su obra y valorar la configuración estética que hay al interior de la misma.

Palabras claves: Artista colombiano, alquimia, arte, fotografía, paisaje.

\begin{abstract}
Jorge Ortiz is one of the most relevant artists in the history of the artistic photography in Colombia. He proposes a new approach for the production and reflection around the configuration of a new photographic language, in which the pictorial and conceptual relationships flows within the explorations of the photographic techniques. This paper seeks to explore the language built by the Master Jorge Ortiz through his work and it also aims at valuing the aesthetic setting within his work.
\end{abstract}

Keywords: Colombian artist, alchemy, art, photography, landscape.

\section{Introducción.}

\section{Recorrido artístico de Jorge Ortiz}

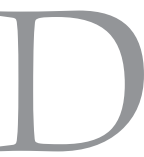
entro de la historia de la fotografía y el arte en Antioquia no se puede dejar de hablar de Jorge Ortiz, uno de los artistas con mayor relevancia en el arte conceptual antioqueño. Ortiz ingresa a la escena del arte local en la década de los años 70 del corrido siglo XX, época en la cual se gesta la denominada Generación Urbana en el contexto del arte joven de la ciudad ${ }^{1}$. Esta sensibilidad se ha ido aguzando cada vez más con el trabajo artístico constante, que aun con sus 66 años de edad, continúa haciendo, con una pasión por la imagen, la creación y el arte que le ha caracterizado en toda su carrera. 
Es así como su obra está cargada de ideas, pues son estas el eje transversal de su creación y de su proceso artístico. Como él mismo manifiesta, "el arte se trata de ideas y no de técnicas" (Ortiz Cancino, 2014). Esta última la ha desarrollado desde una pluralidad fotográfica, la cual ha evolucionado en cuatro etapas -fotografía con cámara (1977-1979), química fotográfica (1980-actual), foto-instalación (1981-actual) y quimigramas a color (1989-actual), etapas que han tenido su propia evolución técnica y conceptual en las últimas cuatro décadas tal y como lo afirma la historiadora Gladis Ramírez Madrid (Ramírez Madrid, 2014). En este recorrido artístico, a la idea de la fotografía se le suman el tiempo, el espacio, la alquimia y, lo más importante, la luz.

A partir de entonces, Jorge Ortiz abandona la cámara, y con ella el desarrollo de la fotografía como idea, para dedicarse plenamente a los procesos de la idea de la fotografía, que entiende en la relación de luz, espacio y tiempo. De todas maneras, jamás queda atrás la conciencia de que la dimensión básica del arte actual es la reflexión sobre el concepto de arte; en este sentido, por analogía con la formulación de Joseph Kosuth, puede afirmarse que todo su trabajo se define desde la fotografía como idea (Fernández, pág. 217).

Su constante preocupación por la idea, la experimentación, la observación y el desarrollo de los procesos le ha permitido hacer de la fotografía técnica, objeto, espacio y cuerpo. En su trabajo Ortiz explora múltiples formas técnicas que lo llevan a explorar todos los lenguajes que proponen los movimientos artísticos, desde la fotografía en papel en blanco y negro, hasta la fotoinstalación, el performance y la pintura, haciendo de ello action painting, minimalismo, expresionismo e impresionismo. Es precisamente la capacidad de Ortiz de navegar por los múltiples lenguajes del arte lo que lo hace un artista, y que su obra contenga elementos y características visuales relevantes para ser uno de los artistas más importantes del arte antioqueño².

\subsection{El lenguaje de la obra de Jorge Ortiz}

Lo que me parece importante de la fotografía es esa esencia, esa síntesis, esa alma que tiene. No necesitas comprar una cámara, necesitas las ideas y un poquito de dinero (Ortiz Cancino, 2004).

El lenguaje con el que se consolida la obra de Ortiz se inscribe en los pensamientos que instauran las vanguardias en el siglo XX en el contexto de las artes plásticas. Estas vanguardias borran los límites técnicos de las
2"Yo realizo la formalización que me da la idea, lo que me permite hacer pintura, escultura, performances y lo que yo quiera, porque como ya te dije yo no trabajo con técnicas sino con las ideas y sino con las i ideas pueden ser como quieran" (Ortiz Cancino, 2014) 
${ }^{3}$ Se entenderá como procesos técnicos las técnicas tradicionales que hacen parte de las Bellas Artes, la pintura,
el dibujo y la escultura. desde la idea multidisciplinar que hibrida los procesos de formalización, provocando así una mixtura de procesos técnicos del hacer artístico ${ }^{3}$. Así, se comienzan a mezclar procesos formales y técnicos ofrecidos por cada uno de los campos disciplinares del arte, promoviendo pinturas que se convierten en objetos, dibujos que se expanden en el espacio, fotografías que usan el lenguaje de la pintura y se construyen con los procesos ofrecidos por la fotografía, y esculturas que son cuerpo, espacio y objeto.

Esa interacción multidimensional responde a una correlación entre unas y otras. Por ejemplo, muchos artistas utilizan elementos de la pintura para la construcción en sí de la imagen, con una intención directa desde la composición. Posteriormente en las vanguardias, después de involucrarse como herramienta de registro de la acción y consecución de una idea plástica, la imagen fotográfica comienza a participar de la obra activamente, abriéndose caminos para generarse como lenguaje.

Es en este contexto de vanguardias en el cual se introduce la obra de Ortiz, donde la fotografía se piensa más como un problema de concepto y menos como un problema técnico y formal. Ya no se trata de pensar en el objeto artístico como el producto de una acción netamente mecánica y técnica. Esto le permite potenciarse como lenguaje expresivo y comunicativo que fundamenta todos sus cimientos de creación en la idea y no en la forma. Es allí donde está imbricada la obra de Ortiz: él introduce en sus prácticas de creación relaciones múltiples entre la idea de la fotografía con las formas de la pintura, la escultura y el dibujo; y experimentaciones que le permiten descubrir a través de las reacciones fotoquímicas otras formas de interpretar los elementos gráficos y visuales contenidos en el problema de la formalización artística de la imagen. Las imágenes construidas se convierten en un conjunto de signos que nacen desde una "arbitrariedad" controlada, como metáfora de la naturaleza, de donde, según él, obtiene todo. La naturaleza le brinda con toda generosidad todas sus formas, que componen su creación. Los hombres no inventan nada, la naturaleza les da todo. Hay que agudizar los sentidos y aprender a ver en ella las formas, los colores, las texturas, las líneas, los puntos y los tonos, allí están y permiten extraerse para la creación plástica (Ortiz Cancino, 2014).

Es desde esta agudeza que Ortiz se da cuenta que la fotografía no es simplemente un problema de la imagen capturada, sino que corresponde 
con un problema de la luz propiamente dicha. Es ella la que crea imágenes que aparecen "mágicamente" sobre el material fotosensible, permitiendo que la obra no se convierta en una mera reproducción de la totalidad que ofrece la naturaleza, como la falsa imagen de un espejo, sino que por el contrario propicia la experimentación dentro de la creación y la idea fotográfica. Esto implica una nueva manera de interpretar el sentido y el hacer técnico dentro del arte fotográfico local. La obra de Jorge Ortiz es, entonces, una experimentación constante del hacer artístico y el análisis de todos los elementos visuales que conforman la imagen.

El trabajo de Ortiz es una reflexión de la luz, el tiempo y el espacio desde la fotografía como idea y no como técnica, elaborada desde los contrastes, en donde siempre está presente el sentido de los opuestos: negativo-positivo, blanco-negro, figuración-abstracción, pintura-dibujo, tridimensionalidadbidimensionalidad, oriente-occidente, efímero-permanente; haciendo de las ideas parte del lenguaje fotográfico y del lenguaje fotográfico parte de las ideas. Esa actitud conceptual es la que rige en los trabajos de Ortiz, la cual lo ha llevado de alguna manera a renunciar a la fotografía como toma, para darle prioridad a su sentido alquimista. Allí el trabajo se apropia de un factor fundamental de la fotografía: la luz que se filtra a través de la cámara. Esto le lleva a eliminar la cámara y a trabajar con los líquidos fotosensibles, exponiendo el papel a la luz, dejando que las imágenes aparezcan, en veces espontáneas, en veces controladas.

Esta acción de pensar la fotografía como idea y no como técnica ha propiciado a su vez que Ortiz piense y explore todos los posibles lenguajes que ofrecen las técnicas del arte, consolidando el suyo particular, el cual va desde un pensamiento pictórico con los químicos fotográficos hasta la posibilidad de pensar el espacio en el cual interviene todo lo que él con el tiempo ha elaborado, aprovechando la exploración química de la fotografía, experimentando todas las posibilidades que le brindan los materiales fotoquímicos. A él lo único que le falta "es tomarse el químico" (Ortiz Cancino, 2014).

\subsection{Los procesos de la obra de Jorge Ortiz:} Descubriendo la alquimia fotográfica

I trabajo artístico de Ortiz se puede definir como una exploración
constante del hacer artístico y la técnica fotográfica, y un acto de
reflexión que tiene como eje central la idea como fundamento de su obra,
cuyos procesos de creación son fortalecidos por las nociones del Dadaísmo 
4"En el proceso de creación-fabricación dadaísta destacaba el principio del azar o automatismo, cuya teorización fue llevada a cabo por Tristán Tzara en el Manifiesto del amor débil y el amor amargo (1920) [...]. Con el azar, el artist no pretende consegui no pretende conseguir mal y estilisticamente, sino darle un significado polémico por el procedimiento de fabricación. También se trat de recuperar la magi original de la obra y la merd " que habia perdido." (Mulet Gu1993, págs. 291-292) de principios del siglo $\mathrm{XX}^{4}$. Es así como Ortiz es un artista que se educa en la tradición del arte moderno, y en el proceso de su trabajo fue capaz de dar el salto de la fotografía concebida como un elemento bidimensional, a la fotografía que interviene un espacio, lo que lo convirtió en uno de los pioneros de la fotoinstalación en el contexto nacional (Ramírez Madrid, 2014).

El trabajo artístico del maestro Ortiz, ha evolucionado en el transcurso de estos 40 años, en los cuales su hacer artístico ha madurado en cuatro etapas: una primera etapa que contempla todos los procesos de experimentación y la idea fotográfica, donde Ortiz asume el acto fotográfico más allá de la captura de imágenes en un tiempo y un espacio determinado, a través de la obturación de una herramienta mecánica: cámara. Él hace de la producción fotográfica una experiencia para construir un paisaje fotográfico desde otra perspectiva, una fotografía que expande la acción fotográfica y construye otras miradas a través de su cámara Mamiya C330, el formato de 6x6 y la imagen a blanco y negro, elementos que con el tiempo se convertirán en unidades conceptuales para su propuesta.

En su segunda etapa, a partir de las obras presentadas en el año 1981 para el Coloquio de Arte no Objetual y la Bienal de Arte de Medellín, descubre las riquezas del trabajo con químicos fotográficos y los soportes fotosensibles, y comienza a realizar exploraciones con su obra. Allí las "fotografías" plantean una nueva reflexión en torno a la producción fotográfica, bajo la cual la mezcla de los elementos formales de la pintura y la utilización de las herramientas del medio fotográfico, abren espacios a una nueva reflexión de lo estético que va más allá de la representación de la imagen, haciendo de las producciones fotográficas una experiencia para construir paisajes desde la experimentación.

Talbot, el filósofo e inventor británico, descubrió la manera de crear formas gráficas y pictóricas a través de la manipulación de los químicos sobre soportes sensibilizados, lo cual fue conocido inicialmente como "dibujo fotogénico". Es necesario recordar que esta técnica se aproxima más a la química fotográfica que al componte formal; de esta manera la fotografía se aleja de la óptica del lente (Galeano Marín, 2000). Debido a esto, se resalta que la fotografía simple y entendida como una representación de la realidad, no alcanza a transmitir intensiones reflexivas, se banaliza y se introduce entre los efectos superfluos de la imagen (Baqué, 2003). Por lo tanto la fotografía para Ortiz es una construcción de conceptos y reflexiones desde la manipulación química y la reflexión de la fotografía como idea, la cual responde, en alguna medida, a la apropiación de esta por los lenguajes artísticos de las vanguardias. 
Para una tercera etapa, la obra de Ortiz pide que el espacio no solo se presente como una reflexión conceptual, sino que comience a ser un elemento formal integrado a la creación, por lo cual el objeto, el espacio y el cuerpo comienzan a integrarse a la ya explorada acción pictórica, gráfica y fotográfica, promoviendo que los conceptos técnicos de la fotografía-como la cámara, el cuarto oscuro, lo negativo-positivo, la película, el barrido entre otros, propios del lenguaje fotográfico se vuelvan ideas para la creación artística y no solo elementos técnicos.

Finalmente, para su última etapa, le suma la exploración con el color -pero no la fotografía a color tradicional- Es posible volver a encontrar en él una propuesta sobre la idea de la fotografía que supera la idea predeterminada de esta. La fotografía a color de Ortiz es una "pintura fotográfica" 5 que le permite ya ser producto de una madurez reflexiva sobre la luz, el espacio, las formas, las figuras, las texturas, los espacios y demás elementos visuales y gráficos que siempre han estado presentes en su manera de construir y pensar. A través de los años ha aguzado su capacidad visual, lo que le ha permitido entender con mayor lucidez la idea de "ver, observar y percibir" (Ortiz Cancino, 2014). Esto le permite ahora hacer del arte una experiencia que es pura intuición, espontaneidad y alquimia; que "hace nacer las superficie cuando las toca" (Gutiérrez, 1993:133) que impulsa la actitud en el cual el azar, la accidentalidad y la arbitrariedad se convierten en oportunidades que él potencializa en medio de la creación de su obra.

El ejercicio de innovación que se mantiene constante, en el hacer creativo de Ortiz, le ha permitido participar en múltiples exposiciones, colecciones y salones a nivel local, nacional e internacional desde 1976, año en el cual hace su primera exposición en la galería de La Oficina en Medellín. A partir de este momento ha expuesto en el salón Atenas, en varios salones regionales y nacionales; ha participado en diversas bienales de arte del mundo como las realizadas en Suiza, Sao Pablo, Argentina y Cuba; ha sido invitado a exponer en los Museos de Arte Moderno de Nueva York, Cali, Medellín y Bogotá; y su obra hace parte de las colecciones de los siguientes museos: Museo de Arte Moderno de Bogotá, Museo de Arte Moderno de Medellín, Museo de Arte Moderno de Cartagena de Indias, Museo de Bellas Artes en Caracas (Venezuela), Colección Foto Fest en Houston, Texas (EE.UU.) y Art Gallery of Western Perth, Perth (Australia).

En los últimos años, la obra de Ortiz ha despertado el interés de varios galeristas jóvenes de Medellín y Bogotá los cuales han volcado la mirada
${ }^{5}$ En este escrito se denomina "pintura fotográfica" a la creación que realiza Ortiz con la acción de los químicos fotográficos que extraen el color de una matriz de papel crepé y lo impregnan sobre e Así describe el proceso el profesor e investigador Armando Montoya: "Jorge Ortiz nos sigue sorprendiendo con sus trabajos cuando interviene el soporte fotográfico soporte fotográrico blanco y negro-. Para el caso particular de las obras 11 primaveras y Boquerón-Santa Elena, el artista armó patrones de formas en colores (matrices en papel crepé) que sugieren el vopé) que sugieren el volas montañas y laderas las montañas y laderas De manera caprichosa recorta, acaricia, rompe, y define pieza por pieza; luego pega cada patrón armado sobre la superficie del papel fotográfico que ya se ha empezado a velar; en consecuencia, con un pince aplica fijador sobre el papel crepé y a su vez lo presiona para que se adhiera a la superficie del papel fotografico. Aquí el tiempo, la luz, y el color derivado del pape crepé, se hacen cómplices fortuitos, y en lo furtivo de su encuentro definen texturas en la obra. iNo hay fórmulas! Sólo la experienci las! Sólo la experiencia permite advertir que el deterioro del color en dicho papel, es apenas la pista para interrumpir el procedimiento. Por último, se retira la matriz que nos deja observar el resultado final. servar el resultado final. El papel crepé depuso el color en el concierto de
los fenómenos alquími-

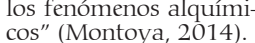


"Jorge Ortiz, obsesivamente vinculado con el tema del paisaje, mantiene un complejo diálogo entre lo metamórfico y lo literal hasta hacer casi imposible discernir entre la obra del artista y e trabajo de la naturaleza" (Fernández, 2006, pág. 216).

${ }^{7} \mathrm{El}$ volumen al cual se refiere Ortiz son las montañas, que enmar-
can el Valle de Aburrá. internacional. Este nuevo acercamiento a la obra del maestro es un paso para comenzar a pensar la importancia de la obra, los procesos y el lenguaje de Ortiz para el arte local y nacional.

\subsection{Los paisajes de Jorge Ortiz}

- Profe, ¿para usted qué es el paisaje?

- El paisaje es todo lo que está al frente mío.

- ¿Por qué el paisaje es el tema de su obra?

- Porque uno debe alimentarse de lo que lo rodea

y yo siempre he estado rodeado de naturaleza.

Ella es la que me entrega toda la sabiduría. (Ortiz Cancino, 2014).

La obra de Ortiz ha vinculado desde el principio una relación con el paisaje, el cual se enlaza a una constante reflexión sobre el medio que lo rodea, de tal forma que los elementos que constituyen el entorno de lo natural y lo urbano estén presenten es su obra en todos los contextos de su hacer artístico. El ambiente natural le es familiar desde su infancia, vivida en casa de sus padres, ubicada en zona rural. Allí establece sus primeras relaciones con los elementos naturales, relación que ha conservado en sus más de 60 años de su vida, por eso los elementos ofrecidos por el entorno son los primeros que aparecen en su obra. ${ }^{6}$

Sin embargo el paisaje que presenta Ortiz desde sus inicios como artista en 1947, trasgrede la concepción costumbrista y propia de la tradición del arte colombiano, brindando otra mirada a su interpretación, la cual ofrece nuevas concepciones estéticas en el marco de las construcciones ofrecidas en el arte contemporáneo local instituido desde los años 60, donde se elimina la mirada nostálgica a los tiempos de antaño, y se propone que se mire a los paisajes que promueve el desarrollo urbano.

Encontraremos entonces en su obra "Cables" (1977-1979) un primer acercamiento a la reflexión de otro horizonte que se extiende hacia arriba y hace de él una referencia del entorno que se promueve desde la construcción de las ciudades. Esto, hace que Ortiz comience a pensar en dos tipos de paisajes: un paisaje que se piensa desde lo urbano y otro que es el paisaje donde se vive en el alto de la tierra que se definirá como los volúmenes ${ }^{7}$, y si se nace en torno de los que ofrecen las montañas, ya no solo se deben pensar como volúmenes, sino que se convierte en superficies, susceptibles de ser reflexiones 
como paisajes naturales que enmarcan el espacio urbano que establece el valle, descubriendo así, una diversidad para representar las múltiples formas en que se devela el paisaje ante los ojos.

De esta forma explora un paisaje que es construido por la luz, el tiempo y el espacio que se proyecta sobre el material fotográfico como idea, en una primera relación de blanco y negro que hace referencia a la luz y a la sombra proyectada sobre el tiempo. Ortiz expande el concepto de paisaje. Para él es natural y espontáneo, y presenta ante sus ojos unas formas que él abstrae para interpretarlas y hacer de lo que lo rodea una imagen perceptual de lo que está frente a él.

Quizá la obra de Jorge Ortiz, obsesivamente vinculado con el problema del paisaje, pero que ha roto de manera radical con la búsqueda de una contemplación bucólica para dedicarse de lleno a la reflexión acerca del proceso estético, ofrece una adecuado punto de referencia acerca de la nueva situación. Desde la serie Cables, inscrita en la mejor tradición del paisaje, que en el arte antioqueño siempre ha estado ligado con el trabajo humano que mira sin falsas nostalgias el progreso, hasta las fotografías de El Boquerón, dedicadas al análisis de los elementos de luz, tiempo y espacio, que posibilitan la fotografía como idea: blanco y negro, luz y sombra en el tiempo. (Fernández, 2006:153-154).

Es desde su serie "El Boquerón" (1980) como Ortiz pasa de lo urbano a lo rural y comienza a realizar una reflexión sobre tiempo, la cual genera una serie de acciones desde el tránsito de los elementos naturales las nubes sobre el espacio. No solo entiende entonces, ese tránsito de tiempo como una temporalidad del día, sino que evidencia la existencia de un lugar que muta constantemente y que ofrece paisajes distintos cada instante. Así él entenderá que el paisaje es uno de día y otro de noche, cambiando en cuestión de segundos.

La idea de Ortiz parte de generar una selección de lo que le ofrece el entorno que le circunda a través de la mirada. Esta acción le permite generar una conciencia sobre el paisaje, que se trabaja primero desde el visor de la cámara fotográfica, y posteriormente desde la acción fotoquímica, lo que le permite pensar ya fuera del dispositivo mecánico y darse cuenta que el paisaje es un constructor de luz, lo cual lo hace un problema de ella y no de la imagen propiamente dicha. Es así como selecciona los mejores de los elementos visuales que le ofrece la naturaleza para hacerla una propuesta fotográfica. 
${ }^{8 " A}$ partir de entonces Jorge Ortiz posibilita que el proceso químico de los materiales fotográficos cree paisaje frente a nosotros, en el tiempo mismo de nuestra experiencia; como Un bosque, un jardín que no es, por supuesto, la reproducción de un paisaje sino una fotografía que es un paisaje que se desarrolla ante nosotros; o en Diafragma abierto, donde la creación de la imagen de paisaje se une con el análisis de los sistemas mecánicos de la cáma mecánicos de la cámara. Ahora es imposible determinar hasta dónd llega el campo del arte y hasta dónde nos envuelve la naturaleza" (Fernández, 2007, pág. 25).

${ }^{9 \prime}$ Es otro paisaje que ya no pretende, como la perspectiva renacentista, encerrar en una sola mirada toda la realidad sino que recorre pacientemente las calles $y$ como dibujos de Óscar identifica como paisaje humano en rostros encontrados corrientes como la vida, pero que nos atrapa de manera irremediable. $\mathrm{O}$, en la fugacidad de la toma fotográfica de Jesís Abad Colorado, dicciones de la vida y la muerte, de la violencia y la ternura, de la razón y de la destrucción, de lo rural y lo urbano, del refinamiento $y$ la supervivencia, de lo artificial y lo natural, las complejas variables de un paisaje demasiado endeble que es imposible de definir. Y en ese recorrido por las calles y plazas, este paisaje y plazas, este paisaje las retóricas falacias de aquella "raza paisa" que sostuvo la pretensión heroica del arte del pasado, porque la ciudad está habitada por nuevas tribus que como Jim Fannkugen, plantea sus propios signos de identidad" (Fernández, 2007, pág. 159).
Ortiz entonces alza la mirada al marco del paisaje que ofrecen el Valle de Aburrá y los cerros que lo enmarcan, potencializando así una manera de entender el paisaje que le es propio y cotidiano. Para él, Medellín está enmarcado por seis pirámides -tres al oriente y tres al occidente- las cuales se miran de frente, y un río que corta el valle. Esta manera de mirar hace que Ortiz expanda el paisaje que observa y lo convierta no solo en una referencia bidimensional, sino en una tridimensional, lo que le permite comenzar a trabajar obras que envuelven al espectador y lo hacen sentir como en el interior del paisaje propiamente dicho. Un ejemplo de ello es "Medellín" (1981), obra que presenta en el marco de la IV Bienal de Medellín, y otro "Un bosque, un jardín" (1996) presentada en el Salón Luis Caballero ${ }^{8}$. En ambas obras Ortiz construye un espacio que el espectador logra transitar de manera análoga y en las que participa de un trayecto paisajístico, en relación a las representaciones del entorno fotoquímico.

Así mismo, con la experimentación fotoquímica rompe con la idea renacentista, en virtud de la cual se propone un paisaje congelado. Por el contrario, Ortiz hace del paisaje un órgano vivo que se trasforma tal cual lo haría el real, aparece y desaparece por la acción activa de los químicos con los cuales se construye, lo que hace de los paisajes de la obra de Ortiz un ejercicio completamente activo y transformable por la acción de la luz, que algunas veces es efímera y que otros procura una permanencia que se hace distinta todos los días 9 .

El paisaje que plantea el maestro Jorge Ortiz es un paisaje que transita desde lo observado, capturado, imaginado y construido en un hacer de la mirada y la memoria que invita a una reflexión del espacio urbano en correlación de lo natural, en una acción donde espacio y tiempo son indispensables en el ejercicio de la representación y la expresión que ofrece el hacer y la práctica de la fotografía. La obra se convierte en una evidencia de la construcción de renovada conciencia y una nueva mirada del paisaje construir ideas en torno al propio espacio que le es cotidiano, que en apariencia pareciese ser el mismo no lo es, pues él siempre lo ve, lo percibe, lo piensa, lo reflexiona y lo ve distinto. A continuación, se presentan las obras que han sido representativas en el recorrido artístico de Ortiz.

\subsubsection{Fotografía, fotograma, fotosíntesis. 2004.}

En la misma línea de "Fotosíntesis" (2003), uno año después, Ortiz realiza "Fotografía, fotograma, fotosíntesis" (2004). Esta se presenta como una 
analogía de la fotografía con la naturaleza a partir de la fotosíntesis, se habla entonces de tres conceptos que tienen como hilo conductor el ejercicio de la luz: fotografía, fotograma y fotosíntesis. Reflexionando así la fotografía como impresión de una imagen, el fotograma como la impresión de una imagen sin la cámara fotográfica que es un problema del laboratorio más experimental y la fotosíntesis, que es realmente lo que Ortiz extrae como concepto y como integración de una idea: luz. Esto le permite concluir que la fotografía es un problema de luz, el fotograma es un problema de luz y la fotosíntesis es un problema de luz. Por ello, comienza desde el título a conservar una relación con la idea y le brinda al espectador una cercanía al concepto que motiva la creación artística.

Este es nuevamente un ejercicio orgánico que se piensa y se renueva constantemente. Si bien el tema es el mismo, la forma de reflexionarse no varía, tanto su pensamiento como su obra son orgánicos; cambian y se trasmutan de manera permanente, de tal forma que "Fotosíntesis" (2003) y "Fotografía, fotograma, fotosíntesis" (2004) es una experimentación que parte del mismo principio pero que se diferencian en el procesamiento de la idea. "Hay muchas formas de formalizarlas. En ese orden de ideas, la fotografía no me ha regalado la técnica fotográfica, sino que me ha regalado la técnica del arte, a partir de la experiencia de László Moholy Nagy"10 (Ortiz Cancino, 2004).

En esa misma línea, Ortiz viene trabajando en la actualidad en otros proyectos, uno de ellos se llamará "Vivero fotosíntesis", en esa relación de estar en una interpretación constante de las ideas, por eso para Ortiz el trabajo creativo no se agota.

\subsubsection{Medellín es un labio 2012}

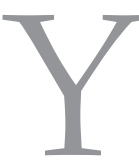

a en los últimos años Ortiz se ha dedicado a reflexionar las formas abstractas que se encuentran en el entorno y que desde esta preocupación construye, resignifica el espacio del valle como paisaje; y que le permite plasmar una construcción simbólica de este y que se presenta como el resumen de la sumatoria de todo el recorrido por esos paisajes construidos en sus obras. "Medellín es un labio" es un volver a mirar a los cerros que bordean Medellín-otra vez Boquerón y Santa Elena mirándose de frente-, pero la forma en que se mira es de manera cenital, posando la mirada desde el cielo observando el valle hacia abajo, lo que le permite extender las líneas que forman el contorno occidental y oriental, lo cual deja en evidencia una figuración que de noche le es propia a los cerros que enmarcan la ciudad;
10"Las fotos de Shad, Ray y Moholy-Nagy representan un cambio sustancial en los hábitos perceptivos tradicionales, una nueva manera de concebir $y$ definir la fotografía, y se engloban en las búsquedas propias de las vanguardias de esos años esos años. Nobstante, aunque los resultados de Man Ray y. Moholy-Nagy son similares, conceptualmente pueden darse ciertas diferencias. Si los rayogramas de Man Ray son el fruto de la Ray son el fruto de la fabricación dadaísta ción, los fotogramas de Moholy . Nagy pretendían ser el producto de un proceso controlado, que incluso teorizó en varios escritos, insisvarios escritos, insismodulares de la luz sobre el objeto. Es decir, a Moholy Nagy parece no interesarle tanto el automatismo, como el estudio científico de la imagen y la búsqueda de sus elementos espe de sus elementos espeel fotograma, o documento de formas, producido por la luz sin cámara encarna la naturaleza única del proceso fotográfico y su verdadera clave Nos permite capturar la reacción mite capturar la reacción de la luz sobre la hoja de
papel sensible sin recurrir papel sensible sin recurrir al uso de ningún apara-
to. El fotograma revela perspectivas de una morfosis, hasta ahora desconocida, que se rige por las leyes ópticas propias. Es el medio más desmadesmaterializado por completo que domina la nueva visión". (Lázlo Moholy Nagy: "Del pigmento a la luz", en Telebor $n^{\circ} 2,1936$. Traducido y reproducido por Joan Fontcuberta, op. cit p. Fontcuberta, op. cit p. 164). (Mulet Gutiérrez págs. 292-293) 


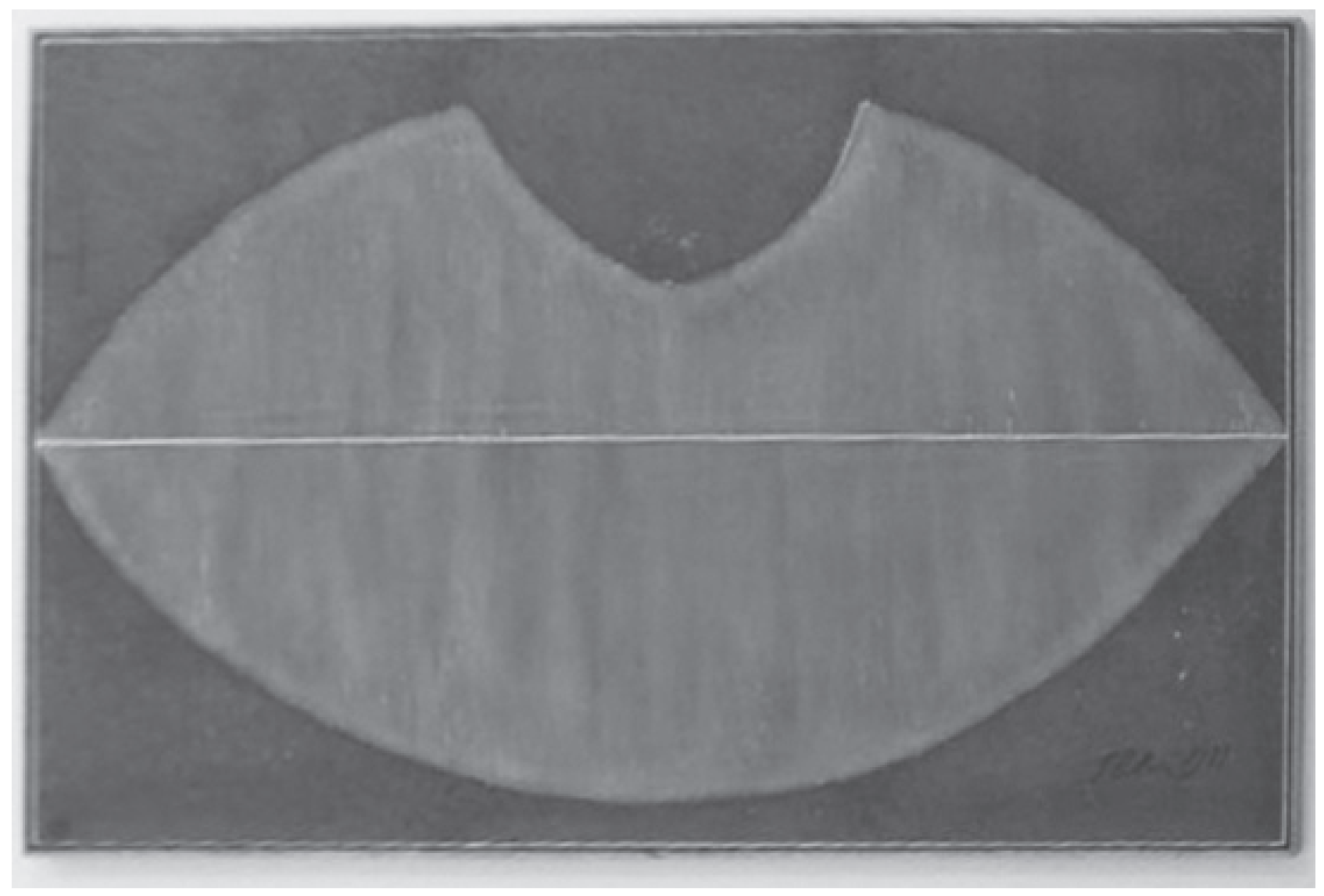

Ilustración 54 Medellín es un labio.

Jorge Ortiz Cancino. 2012. Colección Privada .Medellín - Colombia.

figuración que se corta por la línea del río, por lo que Ortiz permite abstraer el labio inferior que es Santa Elena y el labio superior que es Boquerón.

\subsection{Primaveras - Hitos de geografía urbana. 2011-Actual}

1 1 rimavera - Hitos de geografía urbana" corresponde a la última etapa del desarrollo de la obra de Jorge Ortiz. En ella se nota la madurez del artista y la experiencia que le ha brindado todo su proceso de experimentación técnica. En esta fase, Ortiz ya reflexiona sobre el color en relación con el paisaje como idea central. Vuelve entonces la mirada a todos los entornos que le rodean. Realiza "Primaveras de la mirada de Boquerón" nuevamente, pero desde el detalle, la totalidad, la acción de pensar un hacer del color, desde la experiencia de la pintura y la fotografía.

Para entonces piensa las formas y los colores, y realiza unas matrices de papel crepé en las cuales construye representaciones de los cerros de Medellín y de paisajes que ofrecen múltiples formas. Esta reflexión le permite pensar que 
la imagen ofrece formas distintas de día y de noche. Para Ortiz los árboles son figurativos de noche y abstractos de día, siendo igual para las formas montañosas y para las nubes, de donde salen nuevos temas para su trabajo. En este punto el trabajo de Ortiz se presenta como un expresionismo avanzado, donde la fotoquímica le roba el color al papel crepé y lo impregna sobre los soportes fotosensibles. Un trabajo que madura desde la década de los 90 y ahora se presenta con más fuerza visual, donde los elementos confluyen como un conjunto para la construcción de una imagen sublime, de una interpretación del paisaje fotográfico y pictórico al mismo tiempo.

\section{Conclusiones}

l paisaje como tema para el arte, evoluciona a lo largo de la historia y se construye como objeto simbólico con cargas de significación propias para cada uno de los contextos sociales y culturales desde los cuales se han construido, tanto a nivel local, nacional o en el arte en general; pasando desde simple representación del entorno que rodea al sujeto como lo sería la Expedición Botánica, hasta llegar a convertirse en objeto de representación simbólica de los contextos políticos y sociales, permeado por los procesos de conceptualización del paisaje como parte de la idea del arte. En el contexto nacional y local logramos perfilar una serie de elementos evolutivos que se configuraron a través del tiempo y se trasformaron por medio de la miradas de los artistas que se renovaban respondiendo a los fenómenos sociales y culturales, posibilitando la configuración de nuevas estéticas.

Encontraremos entre ellos el artista Jorge Ortiz, quien propone un paisaje y un hacer del arte que se pueden entender tal y como lo plantea Régis Debray: "el arte como el paisaje son actitudes de concepto", lo que le ofrece a este una serie de elementos que están asociados al intelecto del arte, en el cual se plantea que el paisaje no existe como objeto propiamente dicho, más que una intervención cultural y simbólica (Montoya, 2014). Así, la obra de Ortiz propone otra actitud sobre el paisaje, donde obliga al espectador a asumir una mirada de frente que propicia ver el espacio y el paisaje al mismo tiempo.

Desde el ejercicio de pensar la relevancia que tiene el paisaje en la obra de Jorge Ortiz, se puede concluir que el artista propone una nueva manera de hacer una fotografía del paisaje para el contexto nacional y local, en la cual alude a los principios químicos aboliendo el dispositivo de la cámara y promoviendo una acción desde el pensamiento y el hacer artístico. A partir de estas premisas promueve la idea de pensar la fotografía como idea para la producción, junto 
a una reflexión frente a la luz como elemento primo para la producción de la imagen visual, el tiempo y el espacio como estructuras conceptuales para entender el entorno y construir la obra.

Para ello, utiliza los términos propios del hacer fotográfico para alimentar su obra, estos aparecen de manera recurrente como analogías a ese pensar la luz, el tiempo y el espacio, bien como elementos que posibilitan la formalización brindándole otra mirada al término, usando el término como idea propiamente dicha.

Un ejemplo de ello es el contacto, que es un término que se refiere a la manera de realizar fotografías de manera directa sobre la superficie de la fotografía, muy usada para la construcción de fotogramas o quimigramas y que Ortiz usa de manera recurrente en su hacer técnico para obtener las imágenes, en un juego donde los químicos fotográficos funcionan como canales para la producción de la imagen.

A su vez, la idea del paisaje en el artista es constante desde ese objeto que se observa de frente, se piensa como entorno y se representa como construcción de un paisaje abstracto, en el que priman la conciencia sobre los elementos visuales que lo componen, pero que Ortiz descompone para evidenciar los múltiples paisajes que se encuentran al interior de uno que se concibe completo. Así, se encontrarán entonces paisajes que se construyen a partir de simples líneas, compuestos por las acciones de planos en contrastes o a partir del color o las texturas que le son particulares, pero que al final pueden referir y remitir un imaginario del entorno que sirvió como referente e inspiración.

Sus paisajes ofrecen una actitud mediada entre una conciencia de la naturaleza que lo rodea desde lo urbano y lo orgánico, en una idea de lo mutable. Sus obras cobran vida y se trasforman todos los días, son diferentes por la acción continua que ejerce la luz en sus obras que siempre están acabadas pero no terminadas, pues es la naturaleza -que le brinda todo- la que al final decide si se traga el paisaje devolviéndolo al principio o si lo conserva ante los ojos del espectador. Todo esto brinda una nueva poética a la representación del paisaje en el contexto local.

Ortiz actualmente es un hombre de trabajo constante ya maduro, y con unos aportes significativos en el desarrollo de la idea del arte para el contexto local y nacional. Ver, observar, percibir, experimentar, apropiarse y fundamentar 
la creación en la idea es el legado de su obra. El arte es una experiencia para disfrutarla, "eso es pura contentura" (Fin/dac/feb, 2009).

\section{BIBLIOGRAFÍA}

Baqué, D. (2003). Fotografia plástica. Barcelona: Gustavo Gili, S.A.

Colarte. (s.f.). Eduardo Serrano. Recuperado el 15 de enero de 2015, de Colarte: http://www. colarte.com/colarte/conspintores.asp?idartista $=14923$

Fernández, C. A. (2006). Apuntes para una historia del Arte Contemporáneo en Antioquia. Medellín: Secretaría de Educación para la Cultura de Antioquia.

Fernández, C. A. (2007). Arte en Colombia:1981-2006. Medellín: Universidad de Antioquia.

Fernández, C. A. (s.f.). Los paisajes de Jorge Ortiz: poesía de la luz. Recuperado el 15 de octubre de 2015, de Salauartecontemporaneo's Blog: https://salauartecontemporaneo.wordpress.com/ exposiciones/nubes-en-el-cuarto-oscuro/texto-de-carlos-arturo-fernandez/

Fin/dac/feb. (25 de agosto de 2009). "El arte se trata de la contentura". Recuperado el 15 de enero de 2015, de Agencia de Noticias Universidad Nacional de Colombia: http://www.agenciadenoticias. unal.edu.co/ndetalle/article/el-arte-se-trata-de-la-contentura.html

Galeano Marín, C. A. (2000). Fotografia y arte: Una historia de encuentros y desencuentros. Estudios de filosofía (21-22), 33-56.

Gutiérrez, N. (1993). Jorge Ortiz. Valenzuela \& Klenner. Arte en Colombia Internacional (56), 133.

Montoya, A. (20 de diciembre de 2014). Entrevista personal. (M. L. Molina Saldarriaga, Entrevistador).

Mulet Gutierrez, M. J. \& Seguí Aznar, M. (1993). Fotogafía y vanguardias. Laboratorio de Arte, 279-305.

Ortiz Cancino, J. (28 de marzo de 2004). Programa Voces de color y musica. (C. Velez, Entrevistador) Medellín, Antioquia .

Ortiz Cancino, J. (24 de diciembre de 2014). Entrevista personal. (M. L. Molina Saldarriaga, Entrevistador, \& M. L. Molina-Saldarriaga, Editor) El Retiro, Antioquia, Colombia.

Ramírez Madrid, G. L. (1 de marzo de 2014). Entrevista personal. (M. L. Molina Saldarriaga, Entrevistador, \& M. L. Molina-Saldarriaga, Editor) Medellín, Antioquia, Colombia.

Serrano, E. (2006). Historia de la fotografía en Colombia. Bogóta: Planeta. 